\title{
PSICOLOGIA, AGRICULTURA URBANA, UNIVERSIDADE: O QUE PODEM PÉS DESCALÇOS
}

\author{
Ana Paula Louzada ${ }^{\mathrm{i}}$ \\ Ernesto Grillo Rabello ${ }^{\text {ii }}$ \\ Yan Menezes Oliveira ${ }^{\mathrm{iii}}$
}

"Pero la vitalidad del mundo, que se burla de cualquier clasificación y está más allá de cualquier explicación, no se queda nunca quieta. La naturaleza se realiza em movimiento, y también nosotros, sus hijos, que somos lo que somos y a la vez somos lo que hacemos para cambiar lo que somos. Como decía Pablo Freire, el educador que murió aprendiendo: Somos andando".

Eduardo Galeano

\section{Por uma formação psi afeita à terra}

Tomar o papel como registro, traçar linhas, em vias de tornarmo-nos outros não por imitação, mas por captura, roubo de convivência. Tornar-se planta, tornar-se coletivo. Linhas, como pensava Deleuze (2010), são os elementos que constituem acontecimentos. O presente texto é uma composição de uma cartografia, um diagrama que se faz nos movimentos de corpos que andam e plantam e erram contatos com o desejo, essa usina que pulsa, em meio à formação em psicologia na Universidade Federal do Espírito Santo.

Do que se trata formar? De que matérias (vivas, inumanas) se fazem uma formação? Como se compõem extratos ativos em meio a uma graduação? Como operar em meio às disciplinas e devir uma formação para além e aquém das salas de aulas, e ao mesmo tempo, atravessá-las por experimentações outras?

Movidos por uma tentativa de tatear uma formação em psicologia que amplie as conexões com o vivo, apostando em uma experimentação de modos de existir pouco afeitas às circunscrições e prescrições, compôs-se um coletivo de trabalho disposto a fazer da passagem pela universidade um modo singular de experimentação dos "terrenos" acadêmicos. Compostos de linhas que somos, interessa-nos ver a teia da vida como sistemas vivos (redes) interagindo à maneira de rede com outros sistemas (redes). Assim, cada nó da rede, quando amplificado, aparece, ele mesmo, como uma outra rede. A teia da vida é composta de redes dentro de redes, como escreve Capra (1996).

Embrenhados nessas redes, vive-se a formação em psicologia como um meio ativo de produzir a si em meio às redes vivas. Muito menos que enfocar os sujeitos, os indivíduos, os 
psiquismos, estávamos interessados em atuar e compor uma formação que possa ser de fato atravessada pelos fazeres menores, minoritários, que nos convocassem a tomar a academia por aquilo que diverge. Interessa-nos uma formação como militância, no sentido que Guattari emprega ao termo ${ }^{\text {iv }}$, uma formação psi como política, sobretudo. E essa função pólis, pública, nos convida a arriscar a constituição de novas ferramentas e relações que não aquelas já tão caras à academia, com seus mapas bem desenhados. Experimentar processos formativos afeitos aos cheiros, aos sabores, aos manejos com a terra, tornou-se um modo de ampliar sensibilidades e de nos embrenhar em delicadezas, tão necessárias aos fazeres psi.

Trata-se de experimentar compor uma formação que possa se sujar de mundo. Uma formação afeita ao tempo vivido, na contramão dos processos de aceleração do tempo, e do acúmulo de especializações. Trata-se até mesmo de uma militância utópica, de uma invenção e uma re-invenção constante de novas formas-ativas.

O porvir de todo o planeta e da vida depende das decisões que tomaremos, daqui pra frente. A revolução se quer e se faz, não por dever, mas por desejo ${ }^{\mathrm{v}}$. A existência humana no planeta está cada vez mais atrelada à expansão das áreas urbanas e uma reinvenção das relações sociais nas cidades é imperativa. Quebrar as antinomias homem-natureza, produçãoconsumo, campo-cidade para experimentarmos, juntos, outras composições no contemporâneo é uma via possível em direção a novas produções estéticas ${ }^{\mathrm{vi}}$. Nesse sentido, fazendo devir a graduação em psicologia, apostamos na potência de práticas em Agricultura Urbana, especialmente as que se utilizem da agroecologia como princípio norteador de suas ações. Pensamos e fazemos agroecologia como prática preocupada com a contínua integração, interconexão de processos sociais, ambientais e subjetivos de maneira consciente e sustentável, com o intuito de integrar e trocar saberes e prazeres em linhas de continuidade produtiva.

Desejamos, portanto, inventar outros modos de habitar a Terra, buscando potencializar e dar visibilidade a processos de produção de uma saúde mais integrativa. Nesse sentido, concordamos com a proposta de políticas públicas que visam uma compreensão ampliada dos processos de saúde e doença, bem como tentamos produzir uma psicologia que se permita inventar novas terapêuticas na atenção básica de saúde e que amplie seus "objetos de trabalho" (BRASIL, 2009).

Discutimos, assim, a importância da atuação dos profissionais do campo social, em especial dos operadores psi, como defendia Guattari (2012), na construção e formulação de projetos que visem o engendramento de novos modos de existência diferentes daqueles 
produzidos sob valoração do Capitalismo Mundial Integrado (CMI), valoração na qual a solidariedade e as contribuições comuns se perdem pela descodificação de todos os processos, por tudo aquilo que produzimos e que se produz em nós em torno da axiomática do capital.

\section{Error! AutoText entry not defined.}

Experimentar outras relações com o sagrado, com a Terra, com o cosmos, recompondo singularidades individuais e coletivas. Trata-se da restauração de uma "Cidade subjetiva", como pretendia Guattari (2012), que engajaria tanto os níveis singulares da pessoa quanto os níveis mais coletivos, pois "é a relação da subjetividade com sua 'exterioridade' seja ela social, animal, vegetal, cósmica - que se encontra assim comprometida" (GUATTARI, 2009, p.8). Estamos imersos em uma velocidade de desterritorialização cada vez maior: para Deleuze e Guattari (2004), a máquina capitalista tem como função principal descodificar o desejo e liberar os fluxos que compõem os territórios existenciais e a eles imprimir valores abstratos, capturando-os na sua axiomática de produção e produzindo faltas e necessidades.

Sempre nos falta algo, criamos mais e mais necessidades, mais e mais faltas, faltas que acompanham uma produção tecno-científica-industrial acelerada: produz-se uma visão desintegrada das redes de produção, fazendo delas algo mágico, donde o que se conhece é apenas o produto final. Falamos de consumo em geral: a maneira como consumimos bens materiais, amores, afetos, alimentos, ideias e visões de mundo.

\footnotetext{
"A ordem capitalística produz os modos das relações humanas até em suas representações inconscientes: os modos como se trabalha, como se é ensinado, como se ama, como se trepa, como se fala, etc. Ela fabrica a relação com a produção, com a natureza, com os fatos, com o movimento, com o corpo, com a alimentação, com o presente, com o passado e com o futuro - em suma, ela fabrica a relação do homem com o mundo e consigo mesmo." (GUATTARI \& ROLNIK, 1999, p. 42)
}

Esse processo de produção de necessidades e de mudança nos paralisa por medo mais do que nos move por desejo. Captura-se o desejo em territórios existenciais pré-fabricados que passam a ser co-engendrados por nós mesmos, caso não nos atentemos. Nossos órgãos sensoriais, nossa funções orgânicas, nossos fantasmas, nossos reflexos estão fortemente ligados a um mundo técnico-científico engajado em um crescimento desvairado.

\footnotetext{
“As formações políticas e as instâncias executivas [por sua vez] parecem totalmente incapazes de apreender essa problemática no conjunto de suas implicações. Apesar de estarem começando a tomar uma consciência parcial dos perigos mais evidentes que ameaçam o meio ambiental natural de nossas sociedades, elas geralmente se
} 
contentam em abordar o campo dos danos industriais e, ainda assim, numa perspectiva tecnocrática" (GUATTARI, 2009, p .8)

A tecnocracia investe a produção de subjetividades, investe na forma-ação dos corpos. Foucault (1979) afirma que o capitalismo socializou um primeiro objeto enquanto força de trabalho, força de produção: o corpo. Corpos alvos de estratégias biopolíticas, de um biopoder que produz "fantasmas" e relações espaço-temporais que pretendem um controle midiático e telemático. Uma tecnologia de poder que depende de um conjunto de saberes que julgam e decidem estratégias de intervenção na vida e na disciplina dos corpos. Mas como se esquivar?

\footnotetext{
"Quais são nossos modos de existência, nossas possibilidades de vida ou nossos processos de subjetivação; será que temos maneiras de nos constituirmos como 'si', e, como dirita Nietzsche, maneiras suficientemente 'artistas', para além do saber e do poder?” (DELEUZE, 2010, p. 128)
}

Convoca-se, portanto, a produção de uma existência ética, por oposição à moral. Deleuze (2010) diferencia: a moral como um conjunto de regras coercitivas, que consiste em julgar ações e intenções sob valores transcendentes ("isso é certo, aquilo é errado"); a ética como um conjunto de regras facultativas que se propõem avaliar o que fazemos, dizemos, em função do modo de existência que isso implica.

Apostamos, então, na Vida que se dá na relação, na composição de forças, na produção de novos possíveis. Permitirmo-nos formar um povo de experimentadores, produtor de novos possíveis, aberto às diferenças e que se aproprie da energia do desejo e que produza agenciamentos outros. Um povo que forme alianças, estabeleça conexões, jogue com acoplamentos e invente redes sociais, maquínicas, ecológicas, mentais, espirituais.

Outra pergunta que seguimos: como temos nos relacionado? Guattari, (2009), já alertava que as frases e os gestos de solidariedade desaparecem assim como desaparecem espécies do planeta. $\mathrm{O}$ autor afirma que não há separação entre ações sobre a psique daquelas sobre o socius e o ambiente, pois tudo se organiza em redes, todas as ações implicam intensidades, padrões de interações e iterações, relações entre sistemas vivos e não vivos.

Mas isso ainda não entendemos. Insistimos em brigar pela "proteção da natureza" ou pela "submissão da natureza", como se nos dois casos fôssemos exteriores a ela. Deleuze e Guattari transcrevem uma bela passagem do personagem Lenz, de Büchner:

"pensava que devia ser um sentimento de uma infinita beatitude o ser tocado pela vida profunda de qualquer forma, ter uma alma para as pedras, os metais, a água e as plantas, acolher em si todos os objetos da natureza, sonhadoramente, como as flores 
absorvem o ar com o crescimento e o minguar da lua" (DELEUZE \& GUATTARI, 2004, p. 8)

Reconhecer que já não há nem homem nem natureza (e nem nunca houveram), mas somente um único processo que os liga e os produz, um no outro. É o que os autores chamam de segundo sentido do processo, processo de produção, onde homem e natureza não são termos distintos mas uma mesma realidade, ligados pela energia do desejo no próprio campo de imanência que ele forma (DELEUZE \& GUATTARI, 2004). Tal perspectiva nos permite romper com as dicotomias homem/natureza, cidade/campo, natural/artificial, selvagem/civilizado.

\section{Experimentações em agricultura urbana: Coletivo Planta}

O Coletivo Planta! configura-se como uma organização sem fins lucrativos que pretende, através do cultivo da terra, produzir e difundir uma cultura permanente, interessada na gestão compartilhada e ocupada com a responsabilidade ambiental, mental e social. Um coletivo, surgido de muitos cantos, estágios de vivência com o MST, experiências de viagens diversas, conversas no Centro Acadêmico Livre de Psicologia (CALPSI) e disciplinas no curso de psicologia da Universidade Federal do Espírito Santo. Um coletivo que em março de 2012 fincou o pé no chão e pegou na enxada pela primeira vez.

O espaço do coletivo compreende uma horta em formato de mandala de cerca de 4 metros de raio ao lado do centro acadêmico do curso de Psicologia da UFES. O local é adjacente a passagens importantes da Universidade, próximo ao Restaurante Universitário e à Biblioteca. O espaço, antes grama inutilizada, foi ocupado. Junto à horta, fizemos composteiras e plantio de árvores frutíferas.

O que está em jogo, ao fazermos uma horta, é o papel do profissional psi no contemporâneo. Guattari (2009) contesta o lugar dos intelectuais, sublinhando a responsabilidade dos operadores psi em atuar em conjunto com todos aqueles que podem intervir nas instâncias psíquicas, individuais e coletivas (através da educação, saúde, cultura, agricultura, etc). O autor ainda ressalta que é "eticamente insustentável" se abrigar, como tão frequentemente fazem tais operadores, em um suposto controle do inconsciente e atrás de um suposto corpus científico.

\footnotetext{
"Uma imensa reconstrução das engrenagens sociais é necessária para fazer face aos destroços do Capitalismo Mundial Integrado. Só que essa reconstrução passa menos por formas de cúpula, leis, decretos, programas burocráticos do que pela promoção de práticas inovadoras, pela disseminação de experiências alternativas,
} 
centradas no respeito à singularidade e no trabalho permanente de produção de subjetividade, que vai adquirindo autonomia e ao mesmo tempo se articulando ao resto da sociedade" (GUATTARI, 2009, p.44).

Operadores psi que somos, passamos a ver e fazer da horta um espaço clínico, espaço de produção de subjetividade, espaço de produção de autonomia. A horta como marca forte do desejo imanente, material e social. Desejo na terra e nos corpos que produzem, fortalecidos através do contato de grupo, contato com colaboradores do projeto e contato com a terra.

\section{Diretrizes do Coletivo}

O Coletivo estabeleceu-se através de algumas diretrizes. Buscamos transversalizar a gestão, embaralhar os papéis: diferentemente das gestões verticais, nas quais há uma relação de poder hierarquicamente determinada, e das gestões horizontais, com sua divisão de funções específicas sem hierarquia administrativa, o modo de gestão transversal diz respeito à ausência de poder hierárquico permanente na tomada de decisões administrativas e na permuta constante de funções. Sendo assim, para a transversalidade funcionar, há troca constante de atividades pelos participantes do Coletivo. A aprendizagem é contínua e se faz no próprio processo, se constitui na errância, na ausência de timidez, no direito de errar. Buscamos o desenvolvimento de um conhecimento intuitivo: diferente de um cultivo pautado no nutricionismo ou no cientificismo agronômico, procuramos o contato direto com os processos que ocorram na horta. A partir dos impasses emergidos no campo, buscamos soluções integradas que vão desde adubação orgânica à homeopatia e radiestesia. Perceber, assim, o ritmo dos ciclos das plantas, desacelerar nossos movimentos cotidianos e se atentar para as sutilezas que nos atravessam a todo o tempo, fortalecendo as sensações e trazendo confiança ao corpo. Buscamos acreditar na potência e na inventividade de cada membro do coletivo e, assim, construir um espaço de produção conjunta. Buscamos entender, através dos ciclos de cultivo do próprio alimento, toda a cadeia de produtividade e transporte de alimentos fornecidos à cidade e valorizar projetos de economia local e solidária autossustentáveis. Quanto à seleção e manutenção do cultivo, buscamos a efetuação de um sistema agroecológico, entendendo que a horta deve primar pela harmonia dos conjuntos cultivados, dispensando o uso de qualquer tipo de insumo agrícola; os plantios são feitos em consórcios entre espécies, visando uma maximização da produção através do fortalecimento de espécies afins; os processos de adubação usam os recursos do próprio local através de composteira ou utilizam, no máximo, adubação verde ou orgânica; os materiais de trabalho são reciclados, coletados pelas ruas da cidade; pragas e predadores são vistos como necessários à produção 
de plantas mais fortes e sadias e suas infestações são apenas indicações de que algo não vai bem na dinâmica do ecossistema.

Nessa experiência, produzimos um espaço público que promove encontros, redefinindo, como disse Guattari (2012), as relações entre os espaços construídos e os territórios existenciais da humanidade (e também da animalidade, das espécies vegetais, etc.). Trabalhando juntos, em natureza, criamos uma horta-jardim que é ao mesmo tempo funcional e produtiva. Além disso, a dimensão temporal do cuidado com a terra nos incita uma desaceleração e nos conclama maior atenção àquilo que é pequeno, cíclico, vivo, deslocandonos e reconstruindo o modo como dormimos e acordamos, por exemplo (afinal, há que se regar a horta de manhã bem cedo). Essa mudança é, necessariamente, grupal, uma vez que nos alternamos para executar as tarefas do coletivo.

\section{Do funcionamento}

Funcionamos através de mutirões: determinados dia e hora, nos reunimos, pegamos ferramentas e partilhamos a construção do espaço, desde a feitura de novos canteiros ao plantio de sementes. Temos uma sementeira, nosso berçário, que abriga as mudas a serem ainda plantadas. Nossas ferramentas ficam guardadas dentro do Centro Acadêmico e foram reunidas por nós ao longo do percurso. Também conseguimos apoio da Prefeitura Universitária, que nos empresta ferramentas quando solicitamos. A água utilizada na irrigação da horta vem do Centro Acadêmico. Formamos os mutirões em fins de semana, nos encontramos na UFES e trabalhamos o dia todo, partilhando o alimento do almoço no Centro Acadêmico. As espécies a serem plantadas vêm de vários lugares: de vizinhos, familiares que vivem no interior do Estado, de pessoas que passam pela horta e que oferecem mudas e sementes conseguidas em diversos lugares.

Plantar na cidade e no lugar que escolhemos envolve, porém, certos desafios. Nossas ferramentas, certa vez, sumiram do Centro Acadêmico e até hoje não foram devolvidas. Há também uma grande dificuldade em conseguir terra para concluir os canteiros: apesar de estarmos em um campus grande, a quantidade de terra livre disponível é pouca, somado ao fato da Universidade ter sido edificada sobre um aterro de mangue com terra arenosa e de má qualidade. Pelo mesmo motivo, enfrentamos alagamentos sazonais no campus, o que demandou de nós estratégias de elevação dos canteiros.

Seguimos aprendendo: cada planta tem seu tempo de cultivo até a colheita, há dias do ano bons pra colheita de certas espécies, cada planta aceita bem ou não a companhia de outra 
planta. Mantemos o caráter aberto do projeto: qualquer transeunte que queira participar é bem-vindo e por isso não somos os únicos a colher frutos da horta: o tomate, o boldo, a hortelã podem ser colhidos por qualquer um.

Dos mutirões, temos alguns registros. Mantemos um espaço virtual em uma rede social para compartilhamento de informações e convocações de mutirões. Também mantemos um caderno no Centro Acadêmico, no qual convoca-se a registrar impressões sobre as atividades do coletivo. O caderno contém manuais e cartilhas de agroecologia e relatos de experiência que carregam um forte investimento afetivo do grupo.

O relato, como potência do Coletivo em afirmar sua práxis, torna-se ferramenta na produção de uma memória afetiva do grupo. Transcrevemos aqui um trecho extraído do caderno do Coletivo Planta!:

\begin{abstract}
"Plantar, cuidar, colher e alimentar-se. Plantar amor, cuidar de si, colher contato e alimentar-se de... comida. Sinto o corpo cheio de força e sutileza. Sinto os pés firmes e energizados, as pernas cansadas porém alegres, o ventre pleno e tranquilo, o coração pulsando em potência de escrita e a cabeça leve e clara. Sinto-me desperto, sinto-me vivo. Também, pudera: acordar cedo, rodar a feira orgânica e contatar produtores em buscas de sementes para seguir depois um dia de serviço (e não trabalho, aquele que lembra o instrumento de tortura) junto ao Coletivo Planta! na nossa experimentação em Agricultura Urbana na UFES. Um dia que termina em produção que deseja propagar, contagiar, fazer contato. Produção coletiva ensaiada por duas mãos que, afinal, são muitas. Por hoje, essas duas mãos se compuseram em oito. Duas pra peneirar terra, duas pra cercar canteiros, duas pra cavar e duas pra regar. Revezamento, troca de tarefas e afetos, sempre afetos. As que regavam, passam a colher; as que cercavam, leem sobre consórcio entre mudas; as que peneiravam, vão para a cozinha; as que cavavam, param pra cuidar dos calos. Afirmo que estamos aprendendo: os calos agora compõem o corpo. São marcas da labuta que o serviço na terra traz. Calos de dor, esforço e prazer. Hoje, dia especial, colheita de taioba (oba!) partilhada durante o almoço. Como é bom plantar, cuidar, colher e alimentar-se. Poder, assim, expressar gratidão pelo alimento e por tudo que sentar à mesa com amigos pode trazer: abraços, sorrisos, olhares, energia. Na troca, um de nós afirma: "nunca havia provado um alimento tão bom, plantado e colhido por mim'. É através de dias como esse que falo."
\end{abstract}

Percebe-se que "o relato não se preocupa em transmitir o puro em si do acontecimento, ele o incorpora na própria vida daquele que conta, para comunicá-lo como sua própria experiência àquele que escuta.” (BENJAMIN apud GUATTARI, 2009, p. 53)

Necessariamente, cultivar verduras envolve cultivar afetos. Quanto mais a horta cresce e se torna forte, mais um pequeno ecossistema se cria em torno dela. Gatos, pássaros e animais polinizadores. Ervas daninhas, matos e flores silvestres. O novo espaço pode ter essa 
característica de ser mais maleável do que o espaço público enrijecido, do que um gramado que é só passagem.

\section{Por uma aprendizagem feiticeira}

Manuseios, sabor, cheiros, ervas, grãos, água, sol, movimentos, aprendizagens coloridas de vida. Castañeda (2004) em “A erva do diabo", convida o leitor a compartilhar um outro mundo, propiciado por uso de substâncias alucinógenas que levam o aprendiz-defeiticeiro a um processo de rupturas com os modos usuais de percepção e afecção.

Castañeda (2004) faz falar Dom Juan, velho índio feiticeiro, mestre na arte das ervas e suas composições, mestre cauteloso, cheio de regras e sem pressa. Aprender leva tempo, dizia ele. Suas lições eram silenciosas, rigorosas, e muitas vezes as perguntas precipitadas do aprendiz o irritavam. O aprendiz queria uma aprendizagem na qual ele fosse expectador, e que seu mestre lhe ensinasse tudo o que conhecia sobre as ervas e seus misteriosos poderes, de modo rigoroso e dirigido. Seu mestre insistia em um aprendizado necessariamente corporal e processual. Era necessário dedicar-se e vencer o medo. Deixar velhas crenças, mergulhar no desconhecido. E conhecer passava a ser, então, uma outra forma de viver, um plano imerso em novos afetos e perceptos.

O aprendiz desejava conhecer os instrumentos e Dom Juan insistia que os instrumentos não são essenciais, pois em feitiçaria, qualquer instrumento pode ser um objeto de poder, pois é diretamente relacionado com o bruxo que o utiliza. "Um bruxo forte empresta suas forças a suas ferramentas" (CASTAÑEDA, 2004, p.10). E na sede de conhecer é preciso tomar cuidado para não tentar acumular saber. Saberes não se acumulam. Saberes se usam, pois são instrumentos, ferramentas. Saberes que não se tornam instrumentos são inúteis; os instrumentos só se tornam aliados nos processos de feitiçaria, de vida.

Aprender exige esforço, nenhum conhecimento é dado de presente, afirmava o mestre, é preciso ter disposição, abertura para experimentar o novo, o inusitado. Ao aprendiz era necessário seguir meticulosamente as orientações do mestre, mas esse não sabia como seria sua aprendizagem, ou o que resultaria de suas experiências com as ervas, pois é impossível saber de antemão como vai ser com outra pessoa. Pela perspectiva do aprendiz, isso trazia medo e infelicidade, e o mestre retrucava, dizendo que o medo é o primeiro inimigo, que cada um tem que vencer o seu para conhecer, e vencer o medo era esquecer um pouco de si, perder as formas subjetivadas. Perder-se para encontrar aliados, dizia o mestre, "os temores são 
naturais, todos nós os sentimos e que não há nada a fazer a respeito. Porém, por outro lado, por mais aterrador que seja o conhecimento, é mais terrível ainda pensar num homem sem aliado, ou sem conhecimento" (CASTAÑEDA, 2004, p. 27). O homem que foge de medo pode tornar-se um tirano. É preciso vencer o medo de perder os territórios e avançar.

Quando o aprendiz tentava apressar a aprendizagem das ervas, o mestre impacientavase e dizia que aprender é o destino de uma vida, ou melhor, viver é um constante processo de novas aprendizagens, não há que se ter pressa, um homem não precisa nem precipitar, nem hesitar. É preciso estar disposto, preparado para uma guerra, pois "aprender nunca é aquilo que se espera", coloca Castañeda (2004, p. 43).

Aprender, como capacidade do vivo em divergir (DELEUZE, 2006), aponta para a ruptura dos modelos e das formas. Se, em sua imaterialidade, os desdobramentos do trabalho docente são aprendizagens, sua atividade dá-se em um escorrer entre as formas já dadas e os saberes já consolidados, linhas de imprevisibilidades e de instabilidade.

E além do medo, há outros inimigos a enfrentar. O segundo inimigo é a clareza: quando o homem considerando que já aprendeu tudo, torna-se incapaz de aprender qualquer coisa. É preciso vencer a clareza, pois ela também cega. O terceiro inimigo no processo de aprendizagem é o poder, pois ao avançar nos conhecimentos das ervas o homem toma a si mesmo como poderoso e é preciso vencer essa noção de poder. É preciso desafiá-lo, pois o homem "tem que vir a compreender que o poder que parece ter adquirido nunca é seu" (CASTAÑEDA, 2004, p. 45). Por fim, há um quarto perigo, que é a própria abolição, deixarse levar demasiadamente pelos efeitos das ervas, mergulhar em uma outra percepção e dela não mais se ausentar. Se o medo impedia outras experimentações, a abolição seria habitar indefinidamente os processos de desterritorialização, de devir, puros afetos impessoais. Assim, aprendizagem deixa de ser um instrumento para a vida, pois se corre o risco de abolição, demolição, de morte.

Em meio aos rituais, aos procedimentos, às esperas, e aos delírios provocados pelas ervas, aos longos períodos de jejum, mestre e aprendiz estão a aprender e a estranhar. Aprender é ao mesmo tempo algo que se faz em nós, "você deve descobrir por si mesmo", diz o mestre, e ao mesmo tempo algo que se faz fora de nós. É uma criação de si e do mundo, singularização e produção do comum; rupturas com os procedimentos da modernidade que priorizam a individualização e a totalização. No primeiro modo, aprender é experimentar em 
si e compartilhar com os outros, no segundo aprender é algo que deve se dar em todos, em tal tempo, de tal modo, portanto devem ocorrer em você, em tal tempo, em tal modo; territórios totalizantes e previsíveis.

Nas aprendizagens-feiticeiras não importa nomear, é preciso indagar: o que dá passagem? O que produz sentido? São as passagens, a produção de sentidos, a fabricação de instrumentos, que permitem a invenção de si e do mundo, que forçam a produção da vida como obra de arte, que configuram o pensamento-artista na perspectiva de Deleuze (2010).

Considerações finais

\begin{abstract}
"Viva donde viva, viva como viva, viva cuando viva, cada persona contiene a muchas personas posibles, y es el sistema de poder, que nada tiene de eterno, quien cada día invita a salir a escena a nuestros habitantes más jodidos, mientras impide que los otros crezcan y les prohíbe aparecer. Aunque estamos mal hechos, no estamos terminados; y es la aventura de cambiar y de cambiarnos la que hace que valga la pena este parpadeo en la historia del universo, este fugaz calorcito entre dos hielos, que nosotros somos." (GALEANO, 2009, p. 265)
\end{abstract}

O trabalho do Coletivo Planta! vem sendo realizado com contentamento, com vontade. Em dois anos de trabalho, muitas histórias, muitos afetos, muitos encontros, muitas aprendizagens feiticeiras. As plantas seguem crescendo, atravessando as estações, chuva, sol, calor, frio. Com elas, seguimos nós. Os ciclos se fecham, se abrem: plantamos, colhemos, plantamos de novo.

Aprender a aprender, aprender a fabricar os instrumentos, cultivar sensibilidades e delicadezas, aprender a cultivar no tempo forjado junto com os outros, aprender a cultivar uma espera ativa. Formar-se junto aos coletivos. Formar-se como um meio. Esses tem sido os desafios do Coletivo Planta!.

O trabalho é processo, processo de produção de outras vias, de caminhos outros, caminhos por onde passamos e onde fazemos passar desejo. A vida se dá em movimento e é nesse (e esse) processo que aprendemos, compondo psicologias.

\title{
Referências Bibliográficas
}


BRASIL. Política Nacional de Humanização da Atenção e Gestão do SUS. Brasília: Ministério da Saúde, 2009. 64 p. Disponível em: <http://bvsms.saude.gov.br/bvs/ publicacoes/caderno textos cartilhas politica humanizacao.pdf $>$. Acesso em: 27 jun. 2014; CAPRA, F. A teia da vida: uma compreensão científica dos sistemas vivos. São Paulo: Cultrix, 1996;

CASTANEDA, Carlos. A Erva do Diabo. São Paulo: Editora Record, 2004.

DELEUZE, G. Conversações. São Paulo: Editora 34, 2010.

DELEUZE, G. Diferença e repetição. Rio de Janeiro: Graal, 2006.

DELEUZE, G.; GUATTARI, F. O Anti-édipo: capitalismo e esquizofrenia 1. Lisboa: Assirio e Alvi, 2004.

FOUCAULT, M. Microfísica do Poder. Rio de Janeiro: Edições Graal, 1979.

GALEANO, E. Patas arriba: la escuela del mundo al revés. Coyhaique: Sombayasén Editores, 2009.

GUATTARI, F. As três ecologias. 20a Edição. São Paulo: Papirus, 2009. . Caosmose: um novo paradigma estético. $2^{\mathrm{a}}$ edição. São Paulo: Editora 34, 2012.

13-19. . Somos todos grupelhos. In: Revolução Molecular. São Paulo: Brasiliense, 1987. p.

GUATTARI, F.; ROLNIK, S. Micropolítica: cartografias do desejo. $5^{\text {a }}$ edição. Petrópolis: Editora Vozes, 1999.

\footnotetext{
i Professora Adjunta do Departamento de Psicologia, e do Programa de Pós-graduação em Psicologia Institucional da Universidade Federal do Espirito Santo.

${ }^{\text {ii }}$ Psicólogo, graduado pela Universidade Federal do Espírito Santo

iii Psicólogo, graduado pela Universidade Federal do Espírito Santo Santo

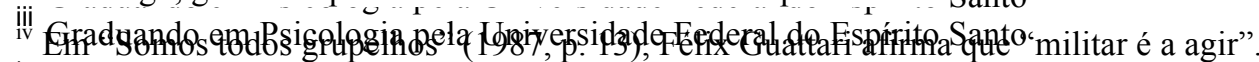

iv Em "Somos todos grupelhos" (1987, p. 13), Félix Guattari afirma que "militar é a agir".

${ }^{v}$ Deleuze e Guattari (2004, p. 360-361) em sua teoria do desejo escrevem que a produção desejante e a produção social são uma e só produção, em determinadas condições. Para que haja mudança social é preciso, portanto, que a revolução aconteça por desejo, e não por ideologia ou dever.

${ }^{\text {vi }}$ Tomamos a expressão de Félix Guattari quando o autor afirma a importância do "engendramento de qualidades de ser inéditas" (2012, p. 121), constituindo um novo paradigma estético onde fazer da vida uma obra de arte torna-se importante para afirmar a diferença e criticar os papéis já estabelecidos no contemporâneo.
} 